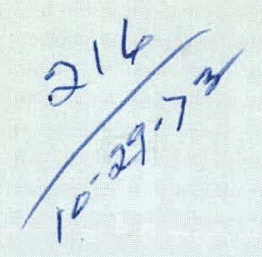

K-1845

\title{
AN EVALUATION OF THE USE OF EDDY CURRENTS TO MEASURE THE THICKNESS OF NICKEL PLATING ON CARBON STEEL
}

J. H. Smith

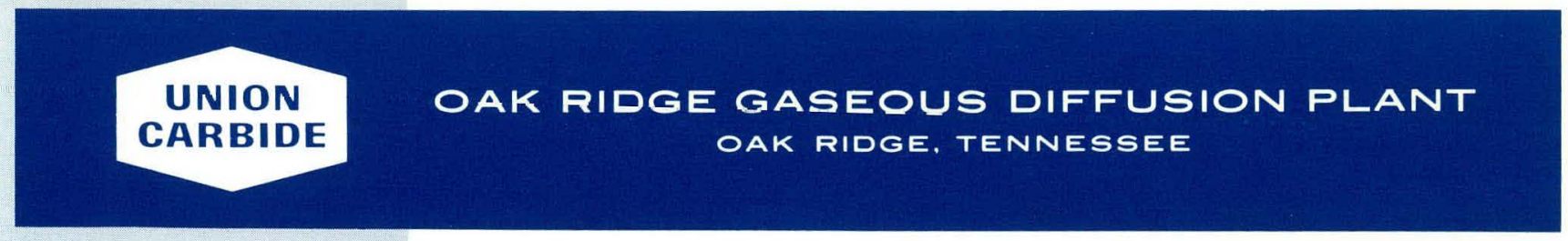

prepared for the U.S. ATOMIC ENERGY COMMISSION

under U.S. GOVERNMENT Contract W.7405 eng 26 


\section{DISCLAIMER}

This report was prepared as an account of work sponsored by an agency of the United States Government. Neither the United States Government nor any agency Thereof, nor any of their employees, makes any warranty, express or implied, or assumes any legal liability or responsibility for the accuracy, completeness, or usefulness of any information, apparatus, product, or process disclosed, or represents that its use would not infringe privately owned rights. Reference herein to any specific commercial product, process, or service by trade name, trademark, manufacturer, or otherwise does not necessarily constitute or imply its endorsement, recommendation, or favoring by the United States Government or any agency thereof. The views and opinions of authors expressed herein do not necessarily state or reflect those of the United States Government or any agency thereof. 


\section{DISCLAIMER}

Portions of this document may be illegible in electronic image products. Images are produced from the best available original document. 
Printed in the United States of America. Available from

National Technical Information Service

U.S. Department of Commerce

5285 Port Royal Road, Springfield, Virginia 22151

Price: Printed Copy \$4.00; Microfiche $\$ 0.95$

This report was prepared as an account of work sponsored by the United States Government. Neither the United States nor the United States Atomic Energy Commission, nor any of their employees, nor any of their contractors, subcontractors, or their employees, makes any warranty, express or implied, or assumes any legal liability or responsibility for the accuracy, completeness or usefulness of any information, apparatus, product or process disclosed, or represents that its use would not infringe privately owned rights. 
AN EVALUATION OF THE USE OF EDDY CURRENTS TO MEASURE

THE THICKNESS OF NICKEL PLATING ON CARBON, STEEL

J. H. Smith

Physical Measurements Department

Laboratory Division

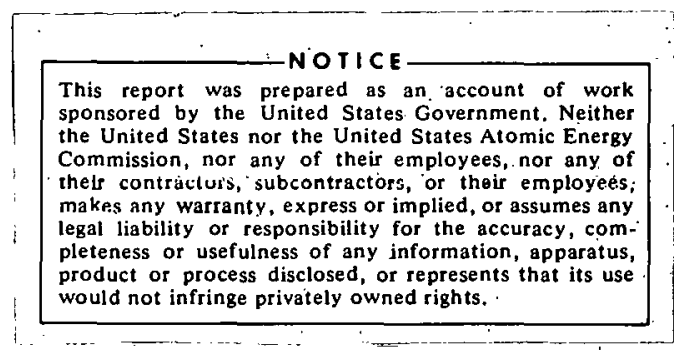

Oak Ridge Gaseous Diffusion Plant
Union Carbide Corporation
nak Ridge. Tennessee

Prepared for the U. S. Atomic Energy Commission under U. S. Government Contract W-7405 eng 26 
THIS PAGE

\section{WAS INTENTIONALLY LEFT BLANK}


ABSTRACT

The capability of using eddy current techniques to measure the thickness of nickelplating on carbon steel is investigated. Factors examined are the influence of: different plating baths (Watts and Sulfamate), different substrates ( $A 285$ and $A 516$ carbon steels), and the effects of using different types of eddy current instrumentation (phase sensitivity versus amplitude sensitivity). The results show that the thickness of nickel plating (for the conditions described in this report) can be measured quite accurately using eddy current techniques, if proper procedures are followed. These procedures are described along with many other variables that are associated with tests of this type. 


\section{THIS PAGE \\ WAS INTENTIONALLY \\ LEFT BLANK}


CONTENTS

Page

INTRODUCTION . . . . . . . . . . . . . . . . . . . 9

SUMMARY . . . . . . . . . . . . . . . . . . . 9

INSTRUMENTATION . . . . . . . . . . . . . . . . 10

Dermitron . . . . . . . . . . . . . . . . 10

Phasen IV . . . . . . . . . . . . . . . . . . . . . 11

Modular Phase Sensitive Eddy Current Instrument . . . . . . Il

PLATING BATHS . . . . . . . . . . . . . . . . . . 11

Sulfamate Bath . . . . . . . . . . . . . . . 11

Watts Bath . . . . . . . . . . . . . . . . . . . . 11

Comparison of the Two Baths . . . . . . . . . . . 12

BASE MATERIALS • • • . . . . . . . . . . . . . . . . 12

PLATING STANDARDS . . . . . . . . . . . . . . . . . . 13

REVERSAL EFFECT • • • . • • • • • • • • • • • • • • • • 15

COMPARISON OF EDDY CURRENT INSTRUMENTS . . . . . . . . . . . . 20

General Discussion . . . . . . . . . . . . . . . . 20

Range of Measurement . . . . . . . . . . . . . . 20

Linearity . . . . . . . . . . . . . . . . . . . . 21

Lift-Off Effects . . . . . . . . . . . . . . . 24

Accuracy ..................... . . 26

EFFECTS OF MATERIAL VARIATIONS ON EDDY CURRENT RESPONSE . . . . 30

Effects of Different Plating Baths . . . . . . . . . . 30

Effects of Different Base Metals . . . . . . . . . . 30

Effects of Grinding the Specimen . . . . . . . . . . 33

Residual Magnetism . . . . . . . . . . . . . . . 33

REFERENCES . . . . . . . . . . . . . . . . . 34 
THIS PAGE

\section{WAS INTENTIONALLY LEFT BLANK}


LIST OF FIGURES

Figure

1

2

3

4

5

6
Title

Page

Eddy Current Response to. Watts Nickel on A516 Steel

Eddy Current Response to Sulfamate Nickel on A516 steel

Dermitron Response at $100 \mathrm{KHz}$ for Five Different Plating Conditions

Phasen IV Response at $5 \mathrm{KHz}$ for Five Different Plating Conditions

Magnitude of the Eddy Current Response at $5 \mathrm{KHz}$ for Five Different Plating Conditions

Phase Shift at $10 \mathrm{KHz}$ for Five Different Plating Conditions 
THIS PAGE

\section{WAS INTENTIONALLY LEFT BLANK}




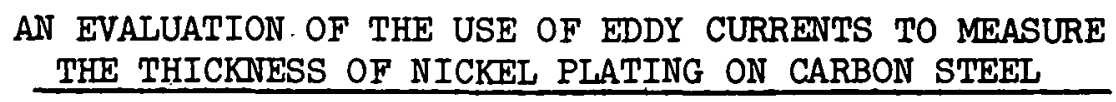

INTRODUCTION

The accurate measurement of the thickness of nickel plating on a carbon steel base using eddy current techniques is not a simple problem. Erroneous results can be obtained if careful control is not exercised over the test. The difficulty stems from the fact that the two materials involved are very similar, and both are ferromagnetic.

In order to obtain useful information from any eddy current test, it is necessary to control the principal variables not being measured, or at least have some knowledge about how they vary. This problem of controlling the variables is accented when the two materials involved are ferromagnetic such as nickel and steel. Processing techniques can cause significant variation in the electrical conductivity and magnetic permeability of these materials. These variations as well as others can affect eddy current response and can lead to errors in the thickness measurement.

Eddy current techniques can be used to accurately measure the thickness of nickel plated on carbon steels provided the tester has some knowledge about how the materials behave under the various test conditions, and provided a sufficient amount of control can be exercised over the test. Control of the test means that; the plating techniques and material preparation techniques should be maintained as uniform as possible to ensure that the plating and base metals do not vary widely from test to test, the inspection techniques should be uniform, and the thickness standards must be representative of the parts being tested.

This report describes a study that was made to determine the effects of changing several of the parameters associated with an eddy current test which involves the measurement of the thickness of nickel plated on steel. The nickel is deposited by an electrolytic type plating process. Two types of nickel plating baths, (Watts and Sulfamate) are evaluated. Two types of base metals (A285, grade $C$ and A516, grade 55 steel) are examined. The study also examines the preparation of plating standards, and compares the capabilities of two different types of eddy current instruments (phase sensitivity versus amplitude sensitivity) for making these measurements.

All references to nickel plating in this report, unless otherwise specified, will refer to nickel deposited from either a Watts type or a Sulfamate type plating bath. All references to steel or to base metal in this report, unless otherwise specified, will refer to either A516, grade 55 or to A285, grade $C$.

\section{SUMMARY}

A reversal effect can occur when eddy currents are used to measure the thickness of nickel plating on mild steel. This effect occurs for both phase sensitive as well as amplitude sensitive eddy current instruments. 'ine type 
of plating bath used (Watts or Sulfamate) will influence the reversal effect. For a given size eddy current coil, the reversal effect is strongly dependent upon the operating frequency of the eddy current instrument. The plating thickness, at which a reversal occurs, increases as the operating frequency is decreased.

A phase sensitive eddy current instrument has several advantages over an amplitude sensitive eddy current instrument insofar as the measurement of the thickness of nickel plated on steel is concerned. The phase sensitive instrument can measure over a wider range of plating thickness, and the response is more linear than that of an amplitude sensitive instrument. The phase sensitive instmument can be calibrated to be insensitive to small variations in lift-off. This feature can be used to prevent scratching and wearing of the reference plating standards, the eddy current probe, and the part being measured.

Base metal variations such as the difference between A285, grade C and A516, grade 55 steel do not cause significant variation in eddy current response to the thickness of nickel plating provided proper measuring techniques are used. There is no significant difference between the eddy current response to nickel plated from a Watts type bath and nickel plated from a Sulfamate type bath for plating thickness in the 0 to $5 \mathrm{mil}$ range when the measuring techniques described in this report are used.

The optimum procedure found in this study that can be used to measure the thickness of (Watts or Sulfamate) nickel plated on (A285 or A516) steel is to use a phase sensitive eddy current instrument such as a Phasen IV, with a type $40 \mathrm{C}$ eddy current probe operated at a frequency of $10 \mathrm{KHz}$. The instrument should be calibrated using plating thickness reference standards made of the same materials as the part to be tested. After the calibration is completed on the reference standards, the zero reference point should be adjusted to correct for any bias between the eddy current response to the base metal of the part being measured and the response to the base metal of the reference standards.

\section{INSTRUMENTATION}

\section{DERMITRON}

Dermitron is a nondestructive thickness tester manufactured by the Unit Process Assemblies Corp. of Woodside, New York.* The instrument uses a wheatstone bridge type arrangement to measure the amplitude of the voltage resulting from the impedance change due to an eddy current reaction. It uses four different test probes which are identified as $A, B, C$, and D. These test probes normally have respective operation frequencies of $100 \mathrm{KHz}$, $500 \mathrm{KHz}, 2 \mathrm{MHz}$, and $6 \mathrm{MHz}$. The instrument is portable, weighs $28 \mathrm{lb}$, and its dimensions are $9 \times 11 \times 17$ in. It operates on $110 \mathrm{v}$ AC power only..

*These identifications are meant to be descriptive, rather than limiting. Other equipment with equal specifications may work equally well. 


\section{PHASEN IV}

The Phasen IV is an eddy current test instrument that was developed at the Oak Ridge National Laboratory. ${ }^{1,2}$ It is marketed by the Tennelec Corp. of Oak Ridge. This instrument measures the phase shift of the voltage resulting from an eddy current reaction. It uses several different probes and comes equipped with either 4 or 6 different operating frequencies. The basic 4 frequencies are $500 \mathrm{~Hz}, 5 \mathrm{KHz}, 50 \mathrm{KHz}$, and $500 \mathrm{KHz}$. (A $10 \mathrm{KHz}$ frequency, recommended for these measurements, may be obtained upon request and existing instruments can be modified to change the operating frequencies.) The instrument is portable, it weighs $6 \mathrm{lb}$ and its dimensions are $5 \times 5-1 / 2 \times 8$ in. It can operate on $\mathrm{AC}$ or $\mathrm{DC}$ power, utilizing rechargeable nickel-cadinium batteries for the DC source.

\section{MODULAR PHASE SENSITIVE EDDY. CURRENT INSTRUMENT}

Some of the data in this report were taken, using this instrument which is located at the Oak Ridge National Laboratory. It measures either the amplitude or the phase shift of the resulting voltage caused by the impedance change accompanying an eddy current reaction. The amplitude or phase response can be related to that of the Dermitron or Phasen IV, respectively. This modular instrument is more versatile, and it was used to obtain data at frequencies which were not available on either the Dermitron or Phasen IV. It was also used to obtain data by an independent technique. This instrument can be calibrated to indicate an absolute phase change, making it independent of calibration by the reference thickness standards.

\section{PLATING BATHS}

\section{SULFAMATE BATH}

There are two basic types of Sulfamate baths. One is an all Sulfamate:bath, and the other contains chlorides. ${ }^{3}$ The chloride type of Sulfamate bath was used to plate the samples described in this report. A brief description of the bath is given below:

$\begin{array}{lll}\text { Nickel-Sulfamate } & \mathrm{Ni}\left(\mathrm{NH}_{2} \mathrm{SO}_{3}\right)_{2} \cdot 6 \mathrm{H}_{2} \mathrm{O} & 58.6 \mathrm{oz} / \mathrm{gal} \\ \text { Nickel-Chloride } & \mathrm{NiCl}_{2} \cdot 6 \mathrm{H}_{2} \mathrm{O} & 5.5 \mathrm{oz} / \mathrm{gal} \\ \text { Boric Acid } & \mathrm{H}_{3} \mathrm{BO}_{3} & 4.6 \mathrm{oz} / \mathrm{gal} \\ \mathrm{pH} & & 3.6 \\ \text { Temperature } & 55 \pm 2{ }^{\circ} \mathrm{C} \\ \text { Current Density, amps/sq ft } & 40 \mathrm{a.s.f.}\end{array}$

WATTS BATH

There are two basic types of Watts baths, a low pH bath and a high pH bath. ${ }^{3}$ The low pH type bath was used to plate the samples described in this report. A brief description of the bath is: 


$\begin{array}{lll}\text { Nickel-Sulfate } & \mathrm{NiSO}_{4} \cdot 6 \mathrm{H}_{2} \mathrm{O} & 50.0 \mathrm{oz} / \mathrm{gal} \\ \text { Nickel-Chloride } & \mathrm{NiCl}_{2} \cdot 6 \mathrm{H}_{2} \mathrm{O} & 12.0 \mathrm{oz} / \mathrm{gal} \\ \text { Boric Acid } & \mathrm{iJ}_{3} \mathrm{BO}_{3} & 5.5 \mathrm{oz} / \mathrm{gal} \\ \mathrm{pH} & & 1.8 \\ \text { Temperature } & 55 \pm 2^{\circ} \mathrm{C} \\ \text { Current Density, amps/sq ft } & 20 \mathrm{a.s.f.}\end{array}$

COMPARISON OF THE TWO BATHS

Comparing the two baths, many advantages and disadvantages are claimed for both. For example, the use of a Sulfamate bath supposedly reduces internal stresses in the deposited nickel. One of the major advantages, from the viewpoint of the plater, is that the Sulfamate type bath can be operated at a higher current density, and thus a given amount of nickel can be deposited in a shorter period of time.

\section{BASE MATERIALS}

A brief description of the two base metals involved in this experiment is given in table 1.4 The basic difference between the two metals is in the chemical requirements.

Table 1

SHFIMT CAT, RFRIITRFIMFINTS

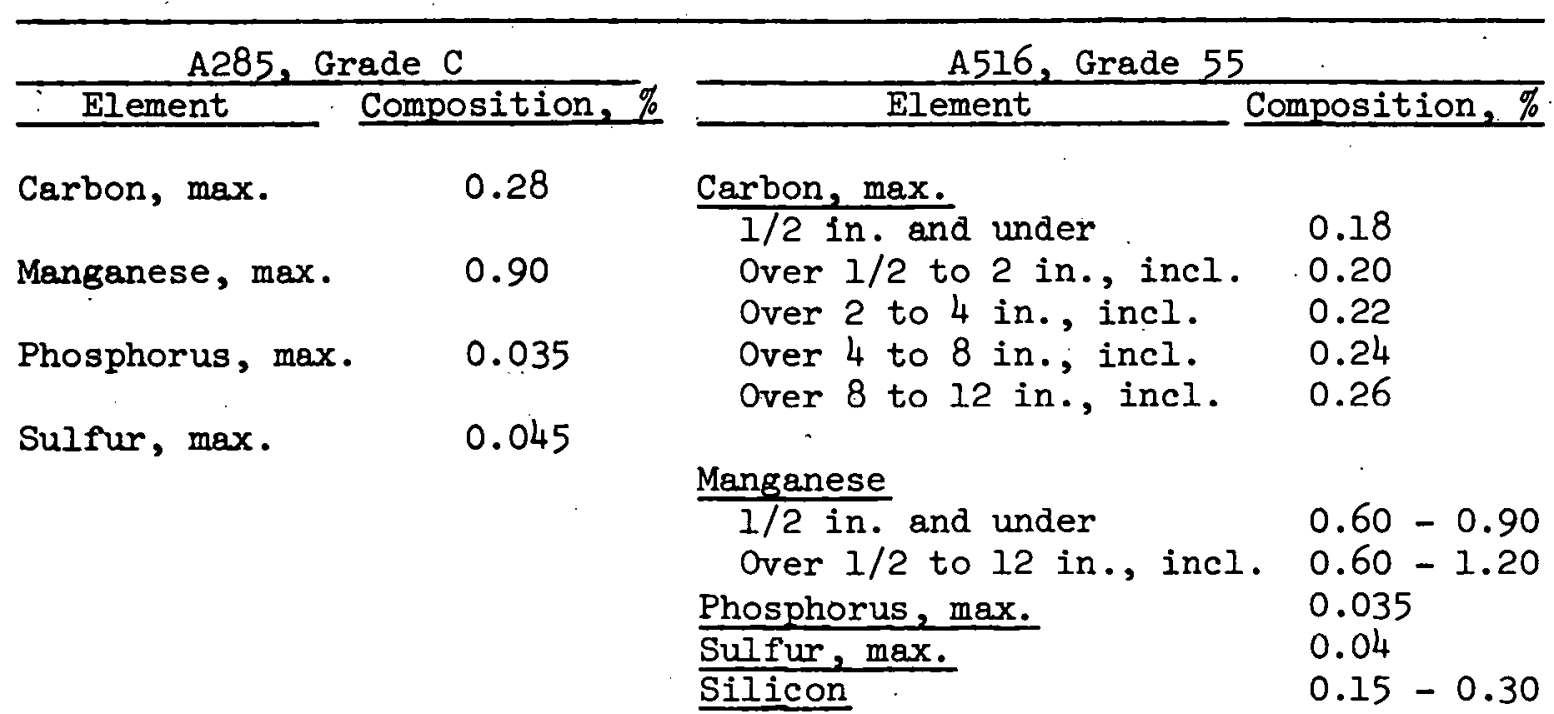


Both materials have the same tensile properties, which are shown in table 2 .

Table 2

TENSILE REQUIREMENTS

\begin{tabular}{lc}
\hline \multicolumn{1}{c}{ Property } & A285, Grade C or A516, Grade 55 \\
\hline Tensile Strength & $55.0-65.0 \mathrm{Ksi}$ \\
Yield Point & $30.0 \mathrm{Ksi}$ \\
Elongation in $8 \mathrm{in.}$ & $23 \%$ \\
Elongation in $2 \mathrm{in.}$ & $27 \%$
\end{tabular}

\section{PLATING STANDARDS}

One set of standards was prepared by plating nickel on A516 steel using a Watts type plating bath. Another set of standards was obtained by plating nickel on A516 steel using a sulfamate type plating bath. The base metal for both sets of samples came from the same piece of grade 55, A516 steel stock. These two sets of standards had plating thicknesses that varied from 0 to about 12 mils, see table 3. A third set of standards was prepared by plating nickel on type A285, grade.C, steel using a Watts type bath.

The A516 steel samples were 1/4- $\times 2-1 / 2-x$ 5-in. plates. The A285 steel sampleswere $3 / 8-\times 2-1 / 2-\times 5-i n$. plates. The faces of all base plates were ground flat and parallel to within 0.0001 in. prior to plating. One face of each steel plate was plated with nickel to a thickness greater than the needed value. The nickel plating was then ground down to obtain the desired thickness. One half of the plated area of each standard was ground to a different thickness, therefore each plate provides two different thickness values.

A (32A80J5VBE) Norton grinding wheel, turning at approximately $1400 \mathrm{rpm}$, was used to grind the nickel plating to obtain the desired thickness. (The thicker, $3 / 8$ in., base plates provided a better heat sink, therefore these samples remained cooler during the grinding process.) All samples were demagnetizied following the grinding process.

The final thickness of the nickel plating on the standards was determined by mechanical as well as metallographic techniques. The metallographic measurements were used to confirm the mechanical measurements, and approximately 50\% of the samples were checked by metallographic techniques. In those cases where metallugruphlc measurements were obtained, the mechanical 
Table 3

PLATING REFERENCE STANDARDS

\begin{tabular}{|c|c|c|c|c|c|c|c|c|c|c|}
\hline \multirow{2}{*}{$\begin{array}{l}\text { Sample } \\
\text { Identity } \\
2\end{array}$} & \multirow{2}{*}{$\begin{array}{c}\begin{array}{c}\text { Type } \\
\text { Plating } \\
\text { Bath }\end{array} \\
\text { Sulfamate }\end{array}$} & \multirow{2}{*}{$\begin{array}{l}\text { Type } \\
\text { A516 }\end{array}$} & & \multirow{2}{*}{ 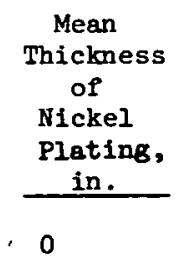 } & \multirow{2}{*}{$\begin{array}{l}\text { Standard } \\
\text { Deviation } \\
\text { for the } \\
\text { Thickness } \\
\begin{array}{c}\text { Measurement, } \\
\text { in. }\end{array} \\
-\end{array}$} & \multicolumn{5}{|c|}{ Comments } \\
\hline & & & Grade 55 & & & Unple & ated & & & \\
\hline 1 & $"$ & $"$ & $"$ & 0.0019 & 0.00007 & & & & & \\
\hline $3 \mathrm{a}$. & $"$ & $"$ & $"$ & 0.0030 & - & Grour & & to $D$ & Desired & Thickness \\
\hline $3 b$ & $"$ & $"$ & $"$ & 0.0036 & 0.00006 & $"$ & & $"$ & $"$ & $"$ \\
\hline $6 a$ & $"$ & $"$ & $"$ & 0.0048 & - & $"$ & & $"$ & $"$ & ' \\
\hline $6 b$ & $"$ & $"$ & $"$ & 0.0060 & 0.00004 & ." & & $"$ & $"$. & $" \quad$. \\
\hline $4 a$ & $"$ & $"$ & $"$ & 0.0066 & - & $"$ & & $"$ & $"$ & $"$ \\
\hline $4 \mathrm{~b}$. & $"$ & $"$. & $"$ & 0.0078 & 0.00010 & $"$ & & " & $"$ & $"$ \\
\hline $5 a$ & $"$ & $"$ & $"$ & 0.0100 & - & $"$ & & $"$ & $"$ & $"$ \\
\hline $5 b$ & $"$ & $"$ & $"$ & 0.0119 & 0.00018 & $"$ & & " & $"$ & $"$ \\
\hline $7 a$ & Watts & A516 & Grade 55 & 0.0011 & 0.00016 & Grour & Ind $t$ & to I & Desired & Thickness \\
\hline To & $"$ & $"$ & $"$ & 0.0020 & - & $"$ & & $"$ & $"$ & $"$ \\
\hline $8 a$ & $"$ & $"$ & $"$ & 0.0033 & 0.00010 & $"$ & & $"$ & $"$ & $"$ \\
\hline $8 b$ & $"$ & $"$ & $"$ & 0.0042 & - & $"$ & & $"$ & $"$ & $"$ \\
\hline $9 a$ & $"$ & $"$ & $"$ & 0.0050 & 0.00004 & $"$ & & $"$ & $"$ & $"$ \\
\hline $9 b$ & $"$. & $"$ & $"$ & 0.0065 & - & $"$ & & " & $"$ & $"$ \\
\hline $10 a$ & $"$ & $"$ & $"$ & 0.0055 & 0.00012 & $"$ & & $"$ & $"$ & $"$ \\
\hline $10 \mathrm{~b}$ & $"$ & $"$ & $"$ & 0.0070 & . & $!$ & & $n$ & $"$ & $"$. \\
\hline 110 & $"$ & $"$ & $"$ & 0.0100 & 0.00030 & $"$. & & $"$ & $"$ & $"$ \\
\hline $11 b$ & " & $"$ & $"$ & 0.0123 & - & $"$ & . ' & $"$ & $"$ & $"$ \\
\hline $12 a$ & Watts & A285 & Grade $C$ & 0.0012 & 0.00017 & Grour & & to I & Desired & Thickness \\
\hline $12 b$ & $"$ & $"$ & ". & 0.0023 & - & $"$ & & $"$ & " & $"$ \\
\hline $13 a$ & $"$ & $"$ & $"$ & 0.0024 & 0.00020 & $"$ & & $"$ & : $"$ & $"$ \\
\hline $13 b$ & $"$ & $"$ & $"$ & 0.0028 & - & $"$ & & $"$ & $"$ & $"$ \\
\hline $14 a$ & $"$ & $"$ & $"$ & 0.0042 & 0.00017 & $"$ & & $"$ & $"$ & ". \\
\hline $140^{\circ}$ & $"$ & $"$ & $"$ & 0.0049 & - & $"$ & & $"$ & $"$ & ". \\
\hline $\mathrm{J} 1 \mathrm{~W}$ & Watts & A516 & Grade 55 & 0.0009 & - & As $\mathrm{P}$ & Plate & ed & & \\
\hline J2W & $"$ & $"$ & $"$ & 0.0014 & - & $"$ & $"$ & & & \\
\hline $\mathrm{J} 3 \mathrm{~W}$ & $"$ & $"$ & $"$ & 0.0022 & - & $n$ & $"$ & & & \\
\hline Jls & Sulfarate & A516 & Grade 55 & 0.0008 & - & & & $\cdots$ & . & ; \\
\hline J2S & $"$ & $"$ & $"$ & 0.0016 & - & $n$ & $"$ & & & \\
\hline J3s & $"$ & $"$ & $"$ & 0.0024 & - & $"$ & $"$ & & & . \\
\hline
\end{tabular}


and metallographic thickness values are averaged and the standard deviations for these values are given in table 3. (These standard deviations include variations due to sample preparation as well as to the thickness measurements.)

The grinding operation provides a potential source of error for an eddy current measurement since grinding can change the magnetic permeability and the electrical conductivity of the materials involved. The grinding was necessary though, in order to prepare reference standards that have a uniform plating thickness over a sufficiently large area to ensure reproducibility in the thickness measurement. The thickness of the nickel plating on steel is nonuniform in the as plated condition, and may vary as much as 20 to $30 \%$ over an area of the size used in this experiment. Due to this large variation in the plating thickness, it is difficult to determine an actual reference thickness of an as plated nickel on steel sample. One technique is to find two spots on a single sample that give the same eddy current response. One spot is sectioned and the thickness is measured metallographically. The second spot is then assigned this thickness value, and the corresponding eddy current response relates to that thickness. It is then necessary to place the eddy current probe on exactly the same area on the standard each time a reference measurement is made. Two sets of as plated samples were obtained for this experiment and their thicknesses, which were determined by the techniques described above, are shown in table 3. Both sets of samples have the same base metal (A516 steel): Samples were obtained for each of the two types of nickel plating baths (Watts and Sulfamate).

\section{REVERSAL EFFECT}

It is possible for the eddy current response to nickel plating thickness on steel to reach a peak or maximum and then reverse, i.e. indicate some value less than maximum, as the plating thickness continues to increase This reversal effect has been noted in testing performed at the Paducah Plant. 5

This effect was examined and the results show that the reversal effect occurs for phase sensitive eddy current instruments (Phasen IV) as well as for amplitude sensitive instruments (Dermitron). The reversal effect is frequency dependent and it varies for different type plating baths. The results can be seen in figures 1 and 2. (The scales used to plot the data in figures 1 and 2 were designed to illustrate the data in single graphs. The vertical heights of the curves do not represent the relative sensitivities of the instruments.)

Figure 1 represents the eddy current response to plating thickness changes for nickel plated on A516 steel from a. Watts type bath. Figure 2 represents the eddy current response to plating thickness changes for nickel plated on A516 steel from a Sulfamate bath. Curves 1 and 4 in each figure represent the response for an amplitude sensitive eddy current instrument operated at respective frequencies of $100 \mathrm{KHz}$ and $5 \mathrm{KHz}$. Curves 2, 3, 5 , and 6 in each figure represent the response for a phase sensitive eddy current instrument operated at frequencie's of $100 \mathrm{KHz}, 50 \mathrm{KHz}, 10 \mathrm{KHz}$, 
DWG. NO. G-73-696

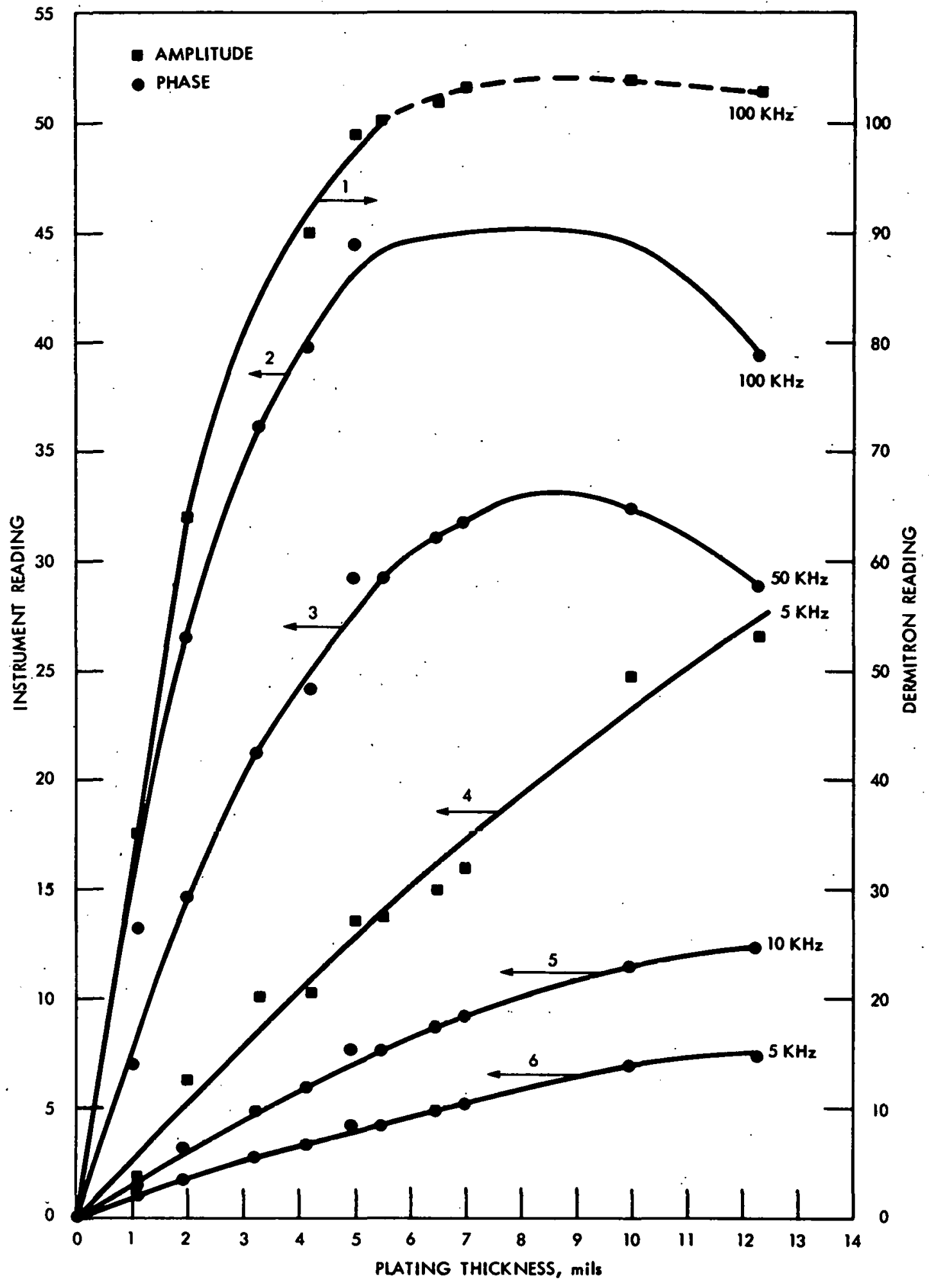

Figure 1

EDDY CURRENT RESPONSE TO WATTS

NICKEL ON A516 STEEL 
DWG. NO. G-73-695

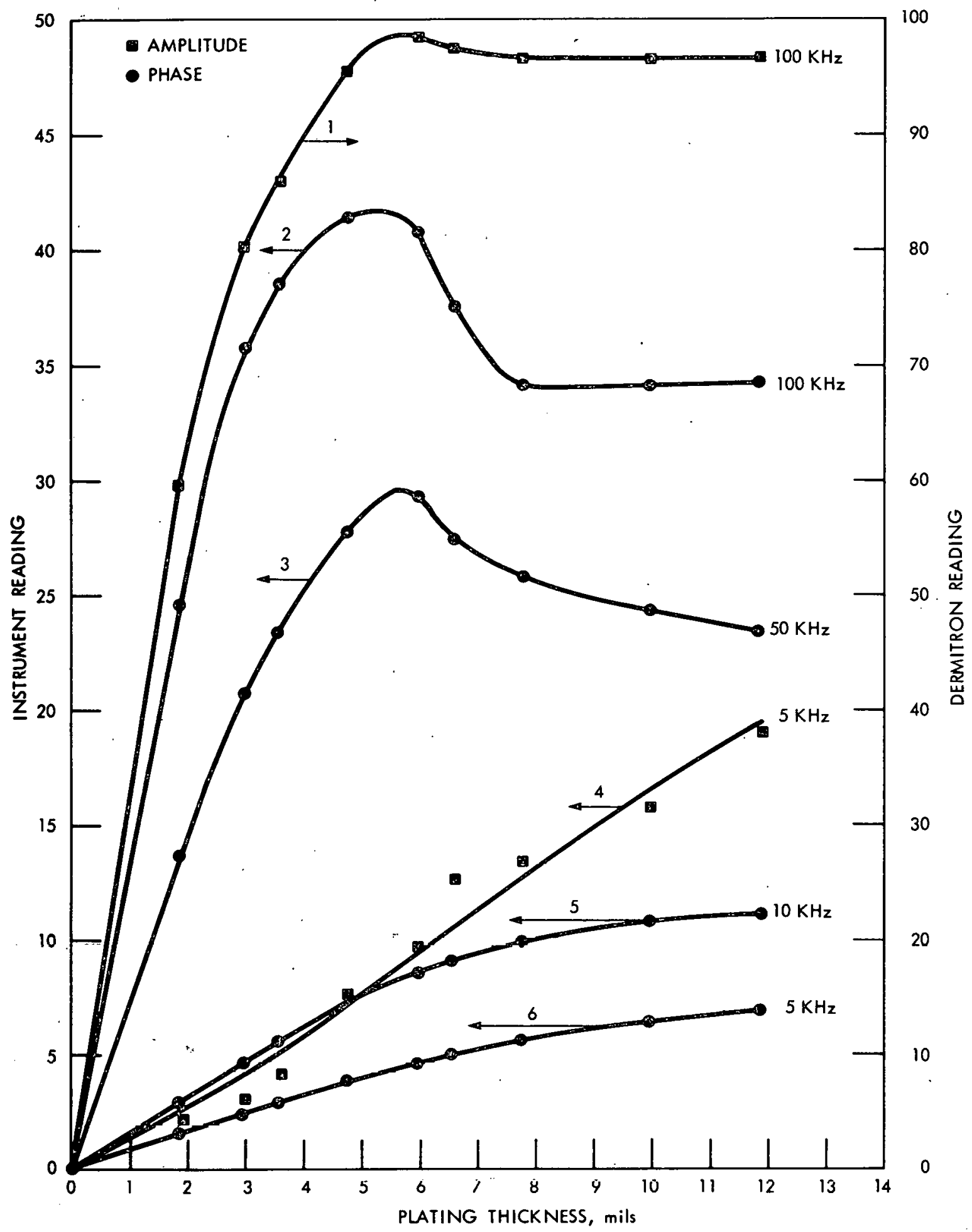

Figure 2

EDDY CURRENT RESPONSE TO SULFAMATE

NICKEL ON A516 STEEL 
and $5 \mathrm{KHz}$, respectively. The arrows indicate the scale to which each curve corresponds. Curve 1 in both figures was recorded using the Dermitron. Curve 1 corresponds to the right hand scale which is divided into units of percent of full scale reading on the Dermitron. The dashed portion of curve 1 in figure 1 was obtained at a half-range setting ( full range $=5$ mils). This technique was not necessary in figure 2 since all data remained on the Dermitron scale.

Curves 2,3, 4, 5, and 6 in figure 1 and figure 2 were recorded using a modular phase sensitive eddy current instrument, see page 11. (The modular instrument can be set-up to indicate either the phase shift or the amplitude of the voltage due to the resulting impedance change from an eddy current response). The modular instrument was used for two reasons: (1) some of the desired operating frequencies were not avallable on the Phasen IV or Dermitron and, (2) this instrument can be calibrated to indicate absolute phase. The absolute phase calibration is independent of the samples being measured, therefore the instruments response to changes in plating thickness will be unbiased by the calibration procedure. The instrument was adjusted to indicate zero phase when the probe was placed on a bare piece of A5I6 steel. (This is not a biasing adjustment. It is merely a shift in the zero point or initial reading). Data obtained with the modular instrument can be directly correlated to data obtained using the Phasen IV or Dermitron operated at the same frequency and under the same conditions.

Curves 2, 3, 4, 5, and 6 correspond to the left hand scale. This scale represents degrees of phase for curves $2,3,5$, and 6 . The scale represents the instrument reading for curve 4 (amplitude at $5 \mathrm{KHz}$ ).

All curves in both figures 1 and 2 were constructed from experimental data points obtained by measuring the samples listed in table 3. Fach experimental data point represents the average of five independent readings, taken with the designated eddy current instrument, at that particular thickness.

The data in figures 1 and 2 show that the reversal effect is frequency dependent. The thickness at which a peak or reversal point occurs varies inversely with the operating frequency. No peak or reversal point could be found at frequencies of $5 \mathrm{KHz}$ and $10 \mathrm{KHz}$, using amplitude or phase sensitivity on either Watts or Sulfamate nickel plated on A516 steel, for plating thicknesses up to $12.3 \mathrm{mils}$ (the maximum thickness available in this experiment).

The reversal point is also dependent upon the type of nickel involved. Note that the reversal points for the Watts nickel on A516 steel, figure 1 , have broader peaks and occur at larger thickness values than the reversal points for Sulfamate nickel on A516 steel, see figure 2, at the same frequencies.

There is little or no difference between the eddy current response to Watts nickel and Sulfamate nickel on $A 516$ steel when the plating thickness is 5 mils or less as shown on curves $1,2,3,5$, and 6 in figures 1 and 2 . 
The only visible difference is in the amplitude data recorded at $5 \mathrm{KHz}$. These curves (curve 4 in each figure) have different slopes. There was also considerably more scatter in the experimental amplitude data recorded at $5 \mathrm{KHz}$.

The reversal effect appears to be a shift of influence (on the eddy current response) from base metal to plated metal as the plating thickness increases. When the plating thickness is less than 5 mils (for the frequencies used in this experiment), the eddy current response is due primarily to the signal which is reflected from the steel base. Over this. thickness range, the amplitude and phase of the reflected signal will vary proportionally with a change in thickness of the nickel plating:

When the plating thickness becomes greater than 5 mils (for the conditions described in this experiment) the nickel begins to insulate the base metal (steel) from the inducing electromagnetic field (especially at frequencies $\geqq 50 \mathrm{KHz}$ ), and the eddy current response becomes more dependent on the effects of the nickel plating. When the plating thickness becomes sufficiently thick, the nickel will completely insulate the steel base from the inducing field, and the eddy current response will be entirely dependent upon the effects of the nickel plating. This insulating thickness. will be some value greater than the reversal thickness. . At this insulating thickness, and for greater plating thickness, the eddy current response should remain uniform with increasing plating thickness.

Referring to figure 2, a nickel plating thickness of 8 mils appears to have been sufficient to completely insulate the steel base from the in-' ducing electromagnetic field at a frequency of $100 \mathrm{KHz}$.

The insulating thickness of nickel plating varies inversely with the operating frequency. This is primarily due to the fact that lower erequency eddy current fields have a greater depth of penetration. For example in figures 1 and 2, operating frequencies of $5 \mathrm{KHz}$ and $10 \mathrm{KHz}$ have a sufficient depth of penetration such that 12 mils of nickel was not thick enough to insulate the steel base from the inducing field thus no reversal points occur at these frequencies over this thickness range.

Another factor that probably influences the reversal effect is the physical size of the eddy current coil. Eddy current response in general is very dependent upon the parameter $\omega \mu \sigma \bar{r}^{2} \cdot 6$

Where:

$\omega$ is the angular frequency of operation, $\mu$ and $\sigma$ are respectively the magnetic permeability and electrical conductivity of the conductor being measured, and

$\bar{r}$ is the mean radius of the eddy current coil. 
The effects of coil size variations were not investigated in this report. All data in this report were recorded using an "A" type probe with the Dermitron, and a $40 \mathrm{C}$ type probe with the Phasen IV and modular instrument. The results shown are representative only for these two probes.

\section{COMPARISON OF EDDY CURRENT INSTRUMENTS}

\section{GENERAL DISCUSSION}

The two instruments, which are compared in this study are the Dermitron and the Phasen IV. These two instmuments are compared because each has been used in the past by one of the gaseous diffusion plants to measure the thickness of nickel plating. One of the objectives of this study was to determine the capabilities and limitations of each instrument for measuring the thickness of nickel plated on steel. The instmments utilize different measuring techniques, the Dermitron is amplitude sensitive and the Phasen IV is phase sensitive. Nearly all eddy current instruments use one of these techniques of measurement therefore, the results of this study should be fairly universal for the frequency and ranges examined.

The two instruments are described briefly on page 10 and 11 of this report. The calibration and operation of both instruments are quite similar. Both are portable. The Phasen IV is smaller, lighter, and can operate from. its own DC power (rechargeable batteries), as well as AC power. The Phasen IV is, therefore, a little more portable than the Dermitron. The other, significant differences between the two instmuments with respect to the measurement of the thickness of nickel plated on steel can be attributed to either the operating frequency or to the mode of operation (phase or amplitude sensitivity). The differences are discussed in the following paragraphs.

\section{RANGE OF MEASUREMENT}

The Phasen IV is capable of accurately measuring thicknesses of nickel plating (on steel) of greater than 12 mils. The maximm thickness of nickel plating (on steel) that can be accurately measured using the Dermitron is about 5 mils. The difference in the measuring ranges of the two instruments is primarily due to the reversal effect, see page 15, and to the lower operating frequency $(5 \mathrm{KHz})$ which is available on the Phasen IV. (The lowest frequency available on the Dermitron is $100 \mathrm{KHz}$. )

The data in figure 1 and 2 show that if nickel plating thicknesses (on steel) of greater than 5 mils are to be measured, an operating frequency of less than $50 \mathrm{KHz}$, and preferably around $5 \mathrm{KHz}$ or $10 \mathrm{KHz}$, should be used. If nickel plating thicknesses of less than 5 mils are to be measured, either instrument can be used. 


\section{LINEARITY}

Linearity of the two instruments is examined in figures 3 and 4. These data were obtained as follows: The Dermitron, ising the " $A$ " probe operated at a frequency of $100 \mathrm{KHz}$, was used to record the data in figure 3. The Phasen IV, using a type "4OC" probe operated at a frequency of $5 \mathrm{KHz}$, was used to record the data in figure 4. Both instruments were calibrated using the 0 and $4.8 \mathrm{mil}$, sulfamate nickel on A516 steel, thickness standards, see table 3. All of the samples listed in table 3 were measured and recorded in figure 4. Only the samples that had plating thicknesses of 5 mils or less are recorded in figure 3. Each point in both figures represents the average of 5 independent instrument readings plotted versus the established mean thickness of the sample.

A computer was used to obtain the best curve fit for the data points in figures 3 and 4, for plating thicknesses of 5 mils and less. A third degree polynominal of the form:

$$
y=a+b x+c x^{2}+d x^{3}
$$

was required to fit the data in figure 3 (Dermitron). The data in figure 4 (Phasen IV), for plating thickness of 5 -mils and less could be fit with a first degree polynominal (straight line) of the form:

$$
y=a+b x .
$$

The data in figures 3 and 4 show that the response of both instruments to changes in thickness of nickel plating on a steel base is nonlinear, but over the 0 to $5 \mathrm{mil}$ range of plating thickness, the response of the Phasen IV is very linear.

All eddy current response is nonlinear to a degree. The extent of nonlinearity will vary with the instrument, the size of the probe, the mode of measurement, the materials being tested, and the thickness range being examined.

Special techniques can be used to correct for nonlinearity when eddy currents are used to measure plating thickness. One method is to construct a table or curve (similar to one of the curves in figures 1 and 2) which correlates the eddy current. response to actual plating thickness using known thickness values. This table or curve can then be used to convert the instrument reading, obtained from an actual test, into plating thickneog values. A second technique is to construct a special nonlinear scale, using known thickness values, and substitute this scale for the normal linear soale that is on the eddy current instrument. If the special scale is properly constructed, the tester can read the plating thickness directly from the instrument.

One of the disadvantages to using corrections of the type just described is that the special scales and/or curves apply only when the same type instrument, eddy current probe, operating frequency, plating material, base material, and certain instmument settings are used. 
DWG. NO. G-73-694

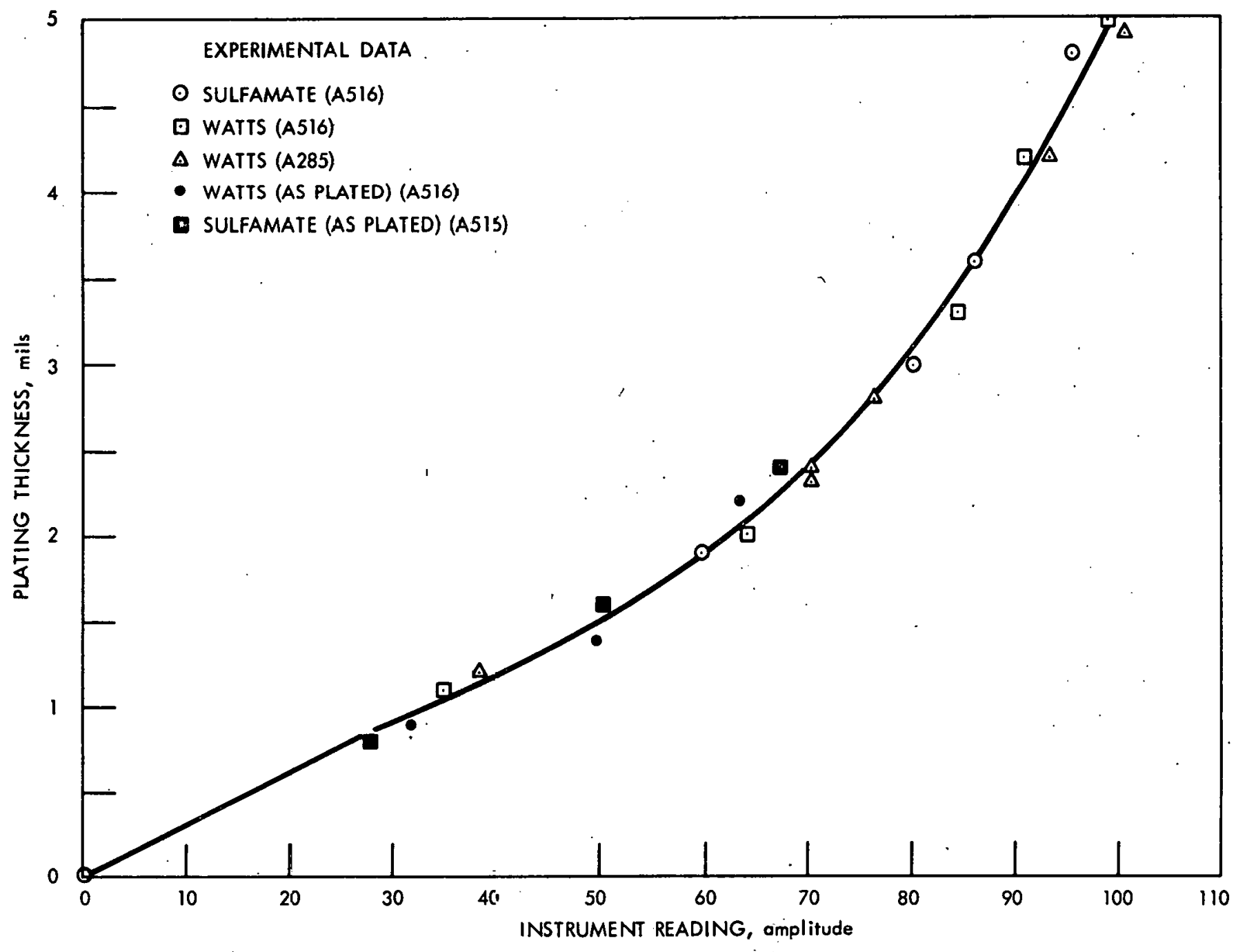

Figure 3

DERMITRON RESPONSE AT $100 \mathrm{KHz}$ FOR FIVE DIF:ERENT PLATING CONDITIONS 
DWG. NO. G-73-693

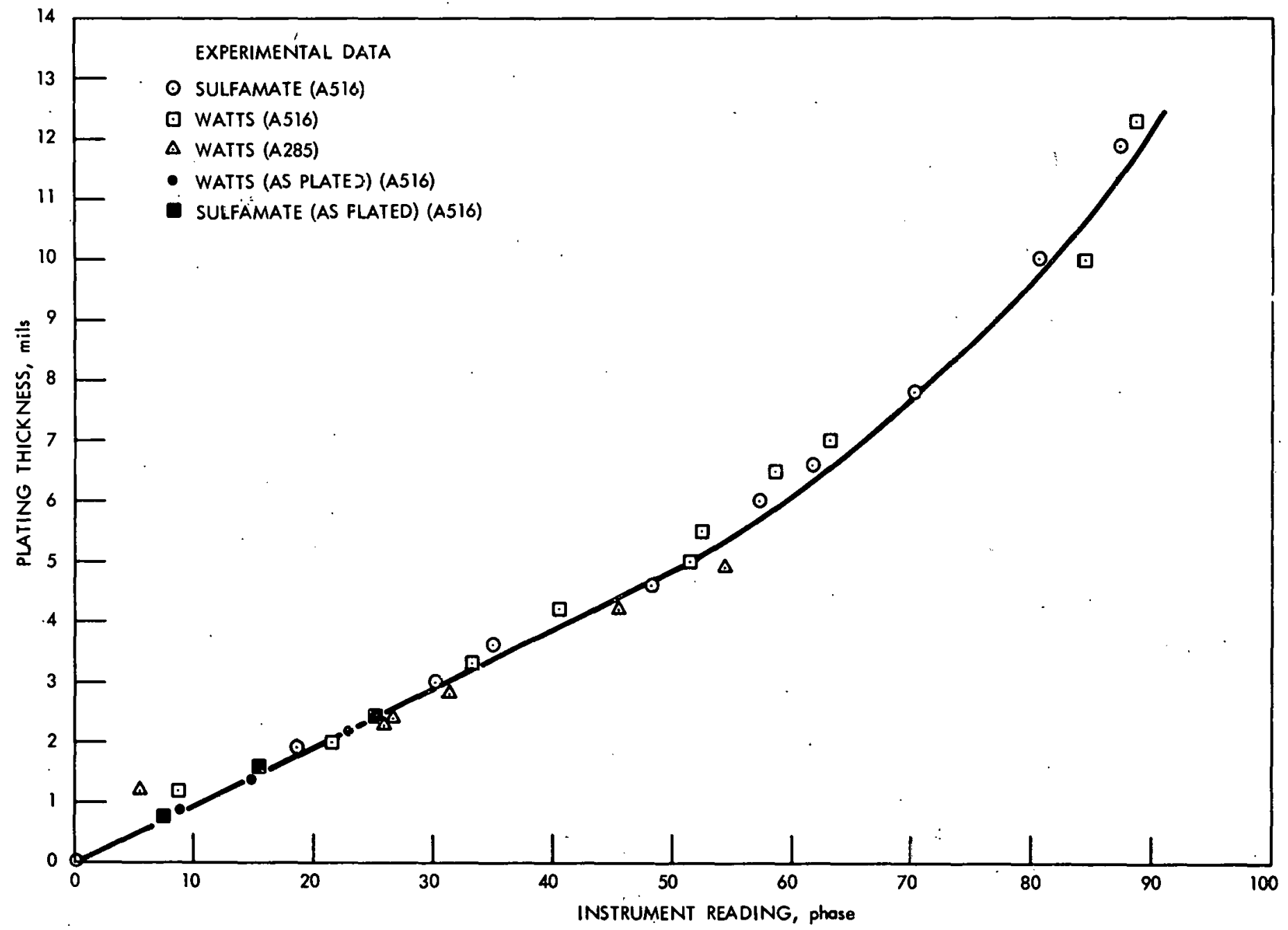

Figure 4

PHASEN IV RESPONSE AT $5 \mathrm{KHz}$ FOR FIVE DIFFERENT PLATING CONDITIONS 
If the Phasen IV (operated at a frequency of $5 \mathrm{KHz}$ or $10 \mathrm{KHz}$ ) is used to measure the thickness of nickel plated on steel in the 0 to $5 \mathrm{mil}$ range, no special curves or scales will be required to correct for nonlinearity. Corrections will be needed only if plating thicknesses significantly greater than 5 mils are neasured.

The modular eddy current instrument, see page 11 , was used to investigate the behavior of an amplitude sensitive eddy current system operated at a frequency of $5 \mathrm{KHz}$. The results are shown in figure 5. All of the samples listed in table 3 were measured, and each point represents the average of 5 independent readings.

No reversal effects could be found at this frequency. As a result, the range of measurement of the amplitude sensitive instrument is extended to greater than 12 mils. The extended range of measurement is gained at the expense of increased scatter in the data and separation of the materials by the amplitude sensitive instrument. The material separation is indicated by the different slopes of the curves. Scatter and separation should be kept to a minimum when the variable being investigated is plating thickness, therefore, it is not advisable to use an amplitude sensitive eddy current instrument, operated at low frequencies ( $\approx 5 \mathrm{KHz})$, to measure the thickness of nickel plated on a steel base.

\section{LIFT-OFF EFFECTS}

Lift-off is an eddy current term that refers to the spacing between the probe or coil and the conductor or part being measured. In general, zero lift-off is employed when amplitude sensitive eddy current instruments are used to make thickness measurements. In other words the probe is in intimate contact with the part being tested. In addition, eddy current response varies with the amount of pressure applied to the probe base. Because of this problem most probes have spring loaded holders to maintain a uniform pressure during measurements. Disadvantages to this contact method of measurement are:

1. Over a long period of use, the probe will wear and will change properties or stop functioning altogether.

2. The thickness reference standards will wear with continued use and will have to be recalibrated or replaced.

3. Delicate surface finishes can be marred by the probe.

A major advantage of a phase sensitive eddy current instrument (over an amplitude sensitive instrument) is in the fact that it can be calibrated to be insensitive to small variators in lift-off (on the order of a few mils). As a result, a small piece of protective tape (such as Milar or Teflon) can be placed over the ends of the probes to prevent any direct contact between the probe and part during testing, and the tape will not affect the accuracy or sensitivity of the test. It may be necessary to replace the tape periodically, but it will prevent the wear of the coil and standards, and will prevent scratching of the surface. The probe and thickness standards should last indefinitely when this procedure is followed. 
DWG. NO. G-73-692

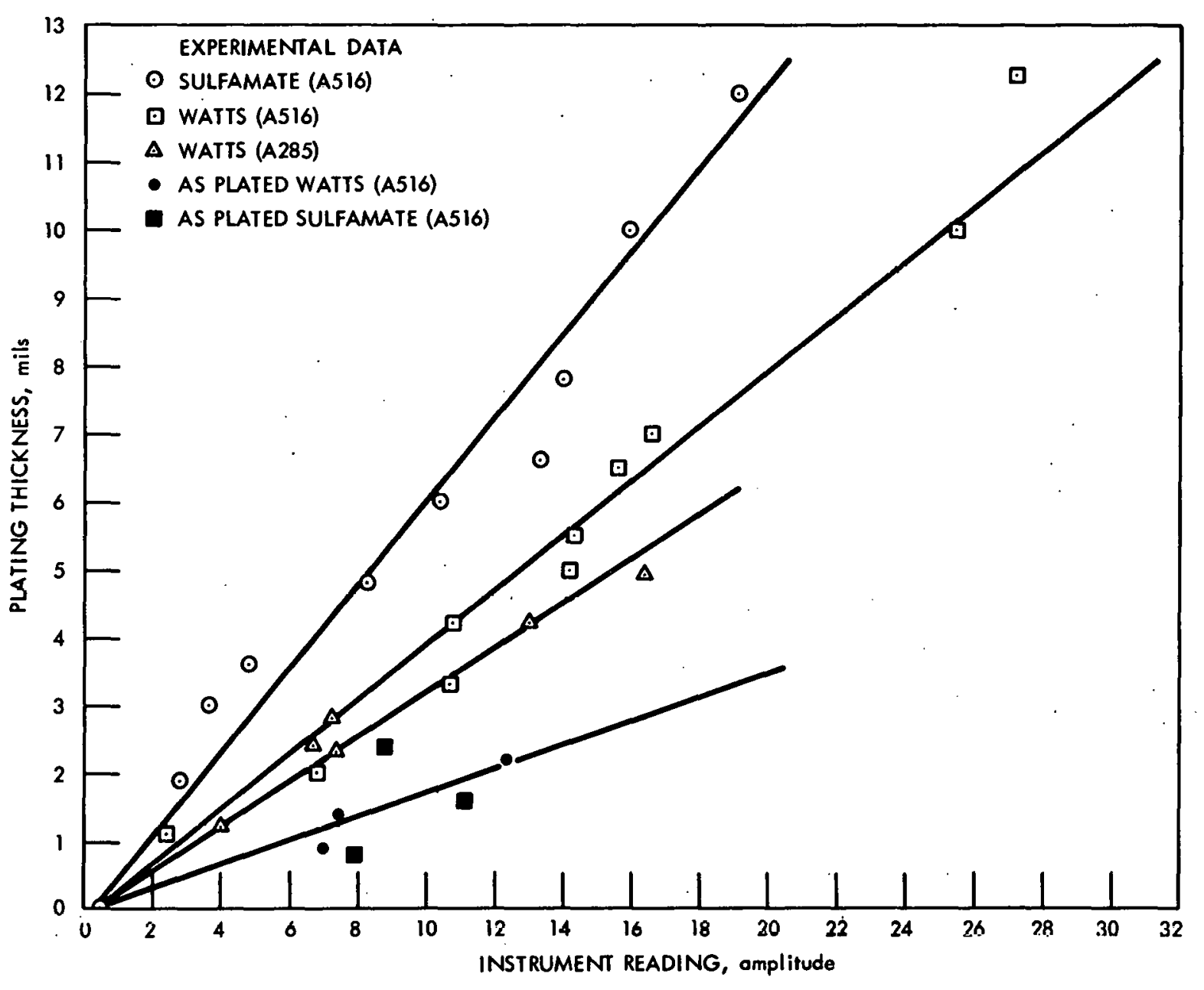

Figure 5

MAGNITUDE OF THE EDDY CURRENT RESPONSE AT $5 \mathrm{KHz}$ FOR FIVE DIFFERENT PLATING CONDITIONS 


\section{ACCURACY}

Statistical techniques were used to investigate the accuracy of the measurements made with the three instruments employed. This experiment utilized five different sets of plated standards, see table 3 . Most of the statistical analysis involves accumulated data from all five sets of samples. Only samples whose thicknesses are 5 mils and less are used in the analysis. This thickness range sufficiently covers the range of interest at the gaseous diffusion plants, and the Dermitron can-measure to only about $5 \mathrm{mils}$ of thickness of nickel plating.

A computer program (POLFIT) was used to obtain the best (least squares) polynominal curve fit for some of the data in this experiment. This program provides two statistical vaiues in addition to fitting the experimental points to a curve. An index of determination is calculated. This is a dimensionless. value that represents a measure of how well the whole of the experimental data fits the theoretical curve. For example, an index of determination of 1 would mean that all of the experimental data points fall on the theoretical curve. "The program also calculates a standard error for the estimate of $y$. (" $y$ " in this case represents the true thickness of the nickel plating). This error (or standard deviation) is expressed in mils and represents the statistical variation of the experimental data points from the theoretical curve.

Table 4 is a tabulation of the index of determination and standard error values for data recorded at several different operating frequencies using a phase sensitive eddy current instrument. The table also includes. amplitude data recorded using the Dermitron at a frequency of $100 \mathrm{KHz}$. The data in table 4 was obtalned as follows:

Table 4

INDEXX OF DETERMINATION AND STANDARD ERROR VALUES

\begin{tabular}{|c|c|c|c|c|c|c|c|c|}
\hline \multirow{2}{*}{$\begin{array}{l}\text { Variable } \\
\text { Measured }\end{array}$} & \multirow{2}{*}{$\begin{array}{c}\text { Frequency } \\
\mathrm{KHz}\end{array}$} & \multicolumn{4}{|c|}{$\begin{array}{l}\text { Index of Determination } \\
\text { for a Best Fit Curve Using } \\
\text { a Polynomial of Degree }\end{array}$} & \multicolumn{3}{|c|}{$\begin{array}{l}\text { Standard Error } \\
\text { Estimate for Y (mils) } \\
\text { for a Bešt Fit Curve Using } \\
\text { a Polynomial of Degree }\end{array}$} \\
\hline & & $I$ & 2 & 3 & 4 & 1 & 2 & 3 \\
\hline Phase & 5 & $0.9895^{\circ}$ & 0.9897 & 0.9898 & 0.9934 & 0.1690 & - & - \\
\hline Phrise & 10 & 0.9952 & 0.9954 & 0.9954 & 0.9971 & 0.1138 & - & - \\
\hline Phase & 50 & 0.9851 & 0.9926 & 0.9944 & 0.9955 & 0.2013 & 0.1450 & - \\
\hline Phase & 100 & 0.9533 & 0.9760 & 0.9786 & 0.9824 & 0.3564 & 0.2612 & - \\
\hline Amplitude & 100 & 0.9284 & 0.9877 & 0.9956 & 0.9956 & 0.4412 & 0.1870 & 0.1142 \\
\hline
\end{tabular}

Five independent sets of thickness measurements were obtained from all samples in table $I$ having plating thicknesses of 5 mils or less. Using the average of these five measurements as the abscissas, and the true plating thicknesses as the ordinates, these points were input into a computer and the best fit polynominal curve was determined. Different degrees of polynominals were 
tried, and statistical data were calculated for each degree of polynominal used. The standard error required quite a bit of computer time and it was only calculated for significant cases.

These data show that, to obtain the most linear curve fit with least amount of error for the criteria defined in this experiment, the optimum operating frequency for a phase sensitive eddy current instrument is 10 $\mathrm{KHz}$. The data at $10 \mathrm{KHz}$ can be fit very well with a first degree polynomial (straight line), and increasing the curve fit to a polynomial. of the fourth degree does not significantly improve its index of determination. The data at $10 \mathrm{KHz}$ also has the smallest standard error. It is interesting to note that the data recorded with the Dermitron at $100 \mathrm{KHz}$ and fit to a third degree polynomial has an index of determination and standard error which are comparable to that obtained using the phase sensitive instrument at $10 \mathrm{KHz}$. This means for example, that if these two calculated curves are used as calibration curves to convert experimental readings into true. thickness values, then the data obtained with the amplitude sensitive instrument at $100 \mathrm{KHz}$ will be almost as accurate as the data obtained using the phase sensitive instrument at $10 \mathrm{KHz}$ (for plating thicknesses of 5 mils and less). The significant difference is that the data obtained with the phase sensitive instrument is linear, and the data obtained with the amplitude sensitive instrument is very nonlinear. The phase sensitive eddy current instrument can aiso measure greater thicknesses of nickel plating, and reversals in readings are not as likely to occur.

Experimental data were recorded using the phase sensitive eddy current instrument at $10 \mathrm{KHz}$. All of the samples in table 3 with thicknesses of $5 \mathrm{mils}$ or less were measured. Five different readings were obtained on each sample and the average value is plotted versus the true thickness in figure 6. The points represent the experimental data. The solid line is the best fit curve to the points which is a first degree polynomial of the form $y=a+b x$. The dashed lines represent the $95 \%$ confidence intervals for a single measurement in the 0 to 5 mil range of plating thicknesșes. This interval varies in width from approximately 0.24 to 0.25 mils. The 95\% confidence interval for the theoretical curve is much smaller. It is less than 0.1 mils wide at the widest point. The best fit curve and the confidence intervals were determined using a computer.

The individual sets of data, except for the as plated samples, were also examined statisticaliy. A statistical analysis of the as plated samples would be very difficult to perform due to the small number of samples available (3) and would be limited due to the small thickness range covered ( 0 to 2 mils). Best polynomial curve fits were obtained for each set of samples examined, using the same experimental data that are plotted In figure 6. The results are shown in table 5.

The indexes of determination show that the three individual sets of data, as well as the accumulated sum of the data, can be fit very well with a first degree polynomial.

The standard deviation was determined for each of the different sets of data, and a statistical "F" test was applied to these standard deviations to deterinine if the differences between them are significant. The results of the "F" test show that only one of the sets of data varies significantly 
DWG. NO. G-73-691

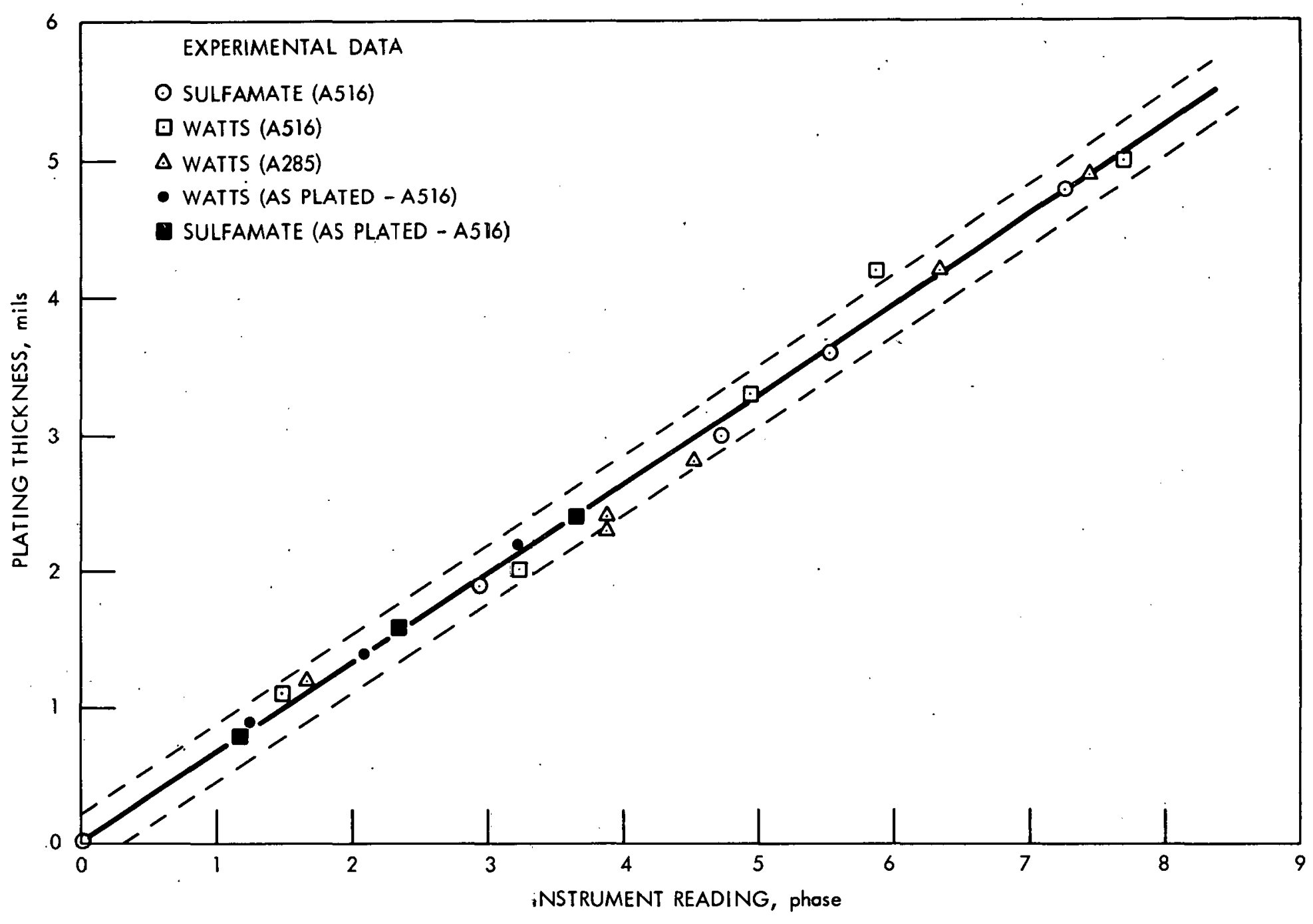

Figure 6

PHASE SHIFT AT $10 \mathrm{KHz}$ FOR FIVE DIFFERENT PLATING CONDITIONS 
A STATISTICAL COMPARISON OF THE DIFFERENT SETS OF PLATED SAMPLES, PHASE DATA RECORDED AT $10 \mathrm{KHz}$

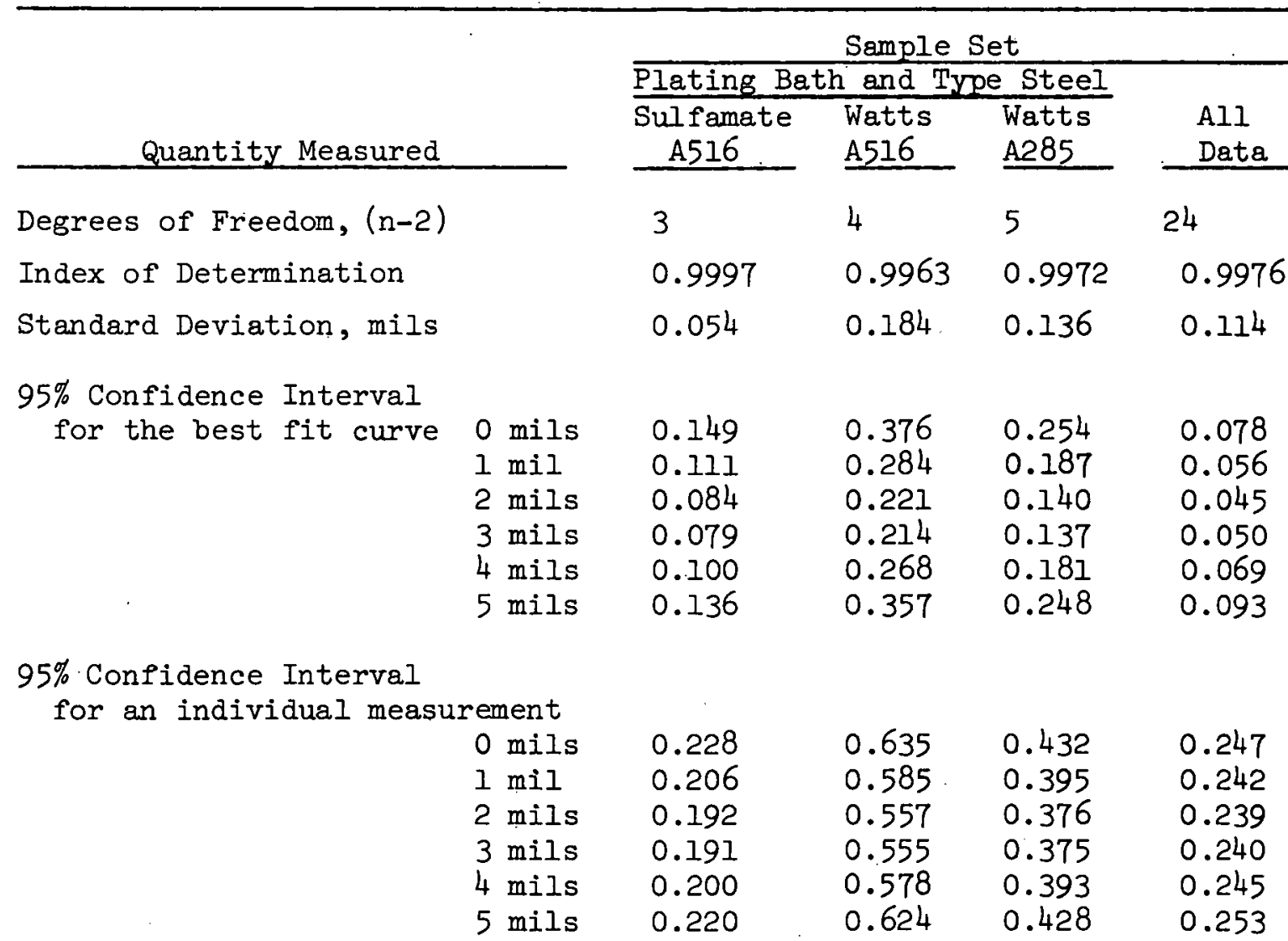

from the others and these are the data corresponding to the Watts nickel on A516 steel. These data include the single point, at 4.2 mils of plating thickness, which falls outside the $95 \%$ confidence interval, see figure 6 . If this point is discarded, then no significant difference can be found between the four sets of data.

An "F" test was also applied to the total data in figure 6 to compare the variation between sets of data to the variation within sets of data, and no significant difference could be found. These results indicate that the accumulated data, in figure 6, from the various sets of samples are homogeneous.

Ninety-five percent confidence intervals were determined for each of the three sets of data, as well as for the accumulated sum of the data. Confidence intervals were determined for a single measurement, and for the best fit curve for each set of data. These results are shown in table 5. The values are given in mils for the indicated thicknesses. 
The smallest confidence interval for a curve is obtained when the interval is determined using the accumulation of all of the data. This is probably due to the increased number of data points available when all of the data are pooled together. The increased number of samples prevails over the fact that the Sulfamate nickel on A516 steel data set has a smaller standard deviation. The Sulfamate nickel on A516 steel data set has the smallest confidence interval for an individual measurement. This is due to the fact that this data set has the smallest standard deviation. In this case the confidence interval is calculated at a single point, and the quantity of data points has less influence.

It should be noted that all of the statistical properties determined in this report include the accumulated error due to sample preparation and certification as well as due to the eddy current measurements.

\section{EFFECTS OF MATERIAL VARIATIONS ON EDDY CURRENT RESPONSE}

\section{EFFECTS OF DIFFERENT PLATING BATHS}

Figures 1,2 , and 5 show that, under certain conditions, significant differences in the eddy current response can be obtained between nickel plated on steel from a Watts bath and nickel plated from a Sulfamate bath. The differences occur in figures 1 and 2 for plating thicknesses greater than 5 mils. The curves for Watts nickel on steel (figure 1) have broader peaks and the peaks occur at greater thickness values than the curves for Sulfamate nickel on steel (figure 2). (These conditions are for operating frequencies of $50 \mathrm{KHz}$ and $100 \mathrm{KHz}$ for both phase sensitive and amplitude sensitive eddy current instmments). A significant difference can also be obtained when an amplitude sensitive eddy current instrument operated at $5 \mathrm{KHz}$ is used to measure the plating thickness. This can be seen by the different slopes of curve 4 in figures 1 and 2 , and for the curves in figure 5 .

No significant difference can be seen in the eddy current response between Watts and Sulfamate nickel on steel when the plating thickness is measured using (refer to figures 1 and 2 ):

1. A phase sensitive eddy current instrument operated at 5 or $10 \mathrm{KHz}$ and the plating thickness is $12 \mathrm{mils}$ or less.

2. A phase sensitive eddy current instrument operated at 5, 10, 50, or $100 \mathrm{KHz}$ and the plating thickness is $5 \mathrm{mils}$ or less.

3. An amplitude sensitive eddy current instrument operated at $100 \mathrm{KHz}$ and the plating thickness is 5 mils or less.

EFFECTS OF DIFFERENT BASE METALS

The data examined so far indicate that, when a phase sensitive eddy current instrument operated at frequencies of $5 \mathrm{KHz}$ or $10 \mathrm{KHz}$, or when an amplitude sensitive eddy current instrument operated at $100 \mathrm{KHz}$, is used to make the 
nickel thickness measurement, no significant difference can be seen in the eddy current response due to differences between the two base metals (A285 and $A 516$ steel). Variations can be seen in the eddy current response due to differences between the base metals when an amplitude sensitive eddy current instrument operated at $5 \mathrm{KHz}$ is used to measure the plating thickness.

A series of measurements were made to obtain further information about the variations due to differences in the base metal and the results are shown in table 6. Samples 1 to 14 are the unplated sides of the samples listed in. table 3. Samples Ml to M7 are pieces of similar steel with varying degrees of heat treatment that were randomly selected from a metallurgical stockpile. The material type and heat treatment information were available for the "M" samples, but no handling or processing history was known. The " $M$ " samples are probably more representative of actual parts than samples 1 to 14 since controlled efforts were made to keep the plated samples uniform.

The data in table 6 is expressed in mils of equivalent nickel plating thickness. This was accomplished by first calibrating the eddy current instrument to indicate nickel plating thicknesses using the 0 and $3 \mathrm{mil}$ nickel sulfamate on A516 steel reference standards (see table 3), and then measuring the eddy current response from the various pieces of bare (unplated) steel. Sample No. 1 was used as the zero thickness reference standard. Each value listed in table 6 is the average of 5 independent readings.

Data were taken, using the Phasen IV, the Dermitron and the modular instrument, operated at respective frequencies of $5 \mathrm{KHz}, 100 \mathrm{KHz}$, and $10 \mathrm{KHz}$. The data taken with the modular instrument utilized phase sensitivity and is representative of data obtained with a Phasen IV operated at the same frequency.

Statistical standard deviations and limits of error at $95 \%$ confidence were calculated for all three sets of data. The statistical limit of error due to variations in the base metal is about 0.0001 in. of equivalent nickel plating thickness for all three cases. The least amount of variation due to differences in the base metal is obtained when a phase sensitive instrument operated at $10 \mathrm{KHz}$ is used to make the measurements.

The data in table 6 indicate that, using the methods described, no significant differences can be seen in the eddy current response due to variations in the base metals examined. These statistical data could be misleading, and should be accepted with caution. The data in this report were recorded under laboratory conditions. Also, statistical theory is based on large numbers of samples. It may be questionable whether or not a sufficient number of different samples were measured in this study to truly represent the total population of base material variations for A285 and A516 steels. It can be seen in table 6 that variations between samples can be greater than 0.0005 in. of equivalent nickel plating thickness. Variations of as large as 0.0005 in. of equivalent nickel plating thickness were also found on a single specimen. In order to be sure that base metal variations are minimized during actual tests, the following calibration technique is recommended. 
Table 6

BASE METAL VARIATIONS

\begin{tabular}{|c|c|c|c|c|c|c|}
\hline $\begin{array}{c}\text { Sample } \\
\text { Identity }\end{array}$ & $\begin{array}{r}\text { Type } \\
\text { Steel } \\
\end{array}$ & Grade & $\begin{array}{l}\text { Equivalent } \\
\text { Phasen TV } \\
\text { e } 5 \mathrm{kHz}, \\
\text { mils } \\
\end{array}$ & $\begin{array}{l}\text { hickness of } \\
\text { Dermitron } \\
\text { e } 100 \mathrm{KHz}, \\
\text { mils } \\
\end{array}$ & $\begin{array}{l}\frac{\text { ickel Plating }}{\text { Modular }} \\
\text { Instrument } \\
\text { e io kHz. } \\
\text { m1ls } \\
\end{array}$ & Comments \\
\hline 1 & A516 & 55 & 0.00 & 0.00 & 0.00 & \\
\hline 2 & $"$ & $"$ & 0.02 & -0.02 & 0.04 & \\
\hline 3 & $"$ & $"$ & -0.05 & -0.09 & 0.03 & \\
\hline 4 & $"$ & $"$ & -0.05 & -0.09 & -0.05 & \\
\hline 5 & $"$ & $"$ & 0.16 & -0.15 & 0.17 & \\
\hline 6 & $"$ & $"$ & -0.08 & -0.09 & -0.08 & \\
\hline 7 & $"$ & $"$ & -0.10 & -0.07 & -0.05 & \\
\hline 8 & $"$ & $"$ & -0.12 & -0.14 & -0.12 & \\
\hline 9 & $"$ & $"$ & -0.12 & $=0.13$ & -0.09 & \\
\hline 10 & $"$ & $"$ & -0.08 & -0.07 & -0.07 & \\
\hline 11 & $"$ & $"$ & -0.15 & -0.12 & -0.10 & \\
\hline 12 & A285 & C & -0.06 & -0.10 & -0.03 & \\
\hline 13 & $"$ & C & 0.13 & -0.04 & 0.08 & \\
\hline 14 & $"$ & C & 0.04 & -0.10 & 0.04 & \\
\hline MI & A516 & 55 & 0.20 & 0.09 & 0.12 & \\
\hline M2 & $"$ & $60-65$ & 0.44 & 0.30 & 0.26 & \\
\hline M3 & $"$ & 70 & 0.40 & 0.28 & 0.24 & \\
\hline M4 & A515 & 55 & 0.36 & 0.06 & 0.20 & \\
\hline M5 & $"$ & $60-65$ & 0.32 & 0.13 & 0.26 & \\
\hline M6 & $"$ & 70 & 0.56 & 0.30 & 0.37 & \\
\hline \multirow[t]{3}{*}{ M7 } & A537 & - & 0.34 & 0.30 & 0.24 & \\
\hline & $\begin{array}{l}\text { Standard } \\
\text { Iimlt of } \\
\text { at } 95 \%\end{array}$ & $\begin{array}{l}\text { Deviation } \\
\text { Error } \\
\text { Confidence }\end{array}$ & $\begin{array}{l}0.219 \\
0.100\end{array}$ & $\begin{array}{l}0.159 \\
0.072\end{array}$ & $\begin{array}{l}0.146 \\
0.066\end{array}$ & $\begin{array}{l}\text { Compare all } \\
\text { samples to sample } \\
\text { No. } 1\end{array}$ \\
\hline & $\begin{array}{r}\text { Standard } \\
\text { Limit of } \\
\text { at } 95 \%\end{array}$ & $\begin{array}{l}\text { Deviation } \\
\text { Error } \\
\text { Confidence }\end{array}$ & $\begin{array}{l}0.168 \\
0.140\end{array}$ & $\begin{array}{l}0.126 \\
0.105\end{array}$ & $\begin{array}{l}0.099 \\
0.083\end{array}$ & $\begin{array}{l}\text { Compare "M" samples } \\
\text { to sample No. } 1\end{array}$ \\
\hline
\end{tabular}


The eddy current instrument should be calibrated in the normal manner using plating thickness reference standards that are composed of the same materials as the part being tested. The eddy current probe should be scanned over an unplated area on the part to be tested. (The response should be checked in several different areas.) If the eddy current response to the base metal on the part varies around some value other than zero, the balance control on the instrument should be adjusted until the response does vary around zero. The calibration of the instrument will not be affected if only the balance control is used to make this adjustment. Thickness measurements can be made when this step is completed.

Considering the data obtained in this report, if the above procedure is followed and proper eddy current techniques are used, little error should result in the measurement of the thickness of nickel plating (in the 0 to $5 \mathrm{mil}$ range) due to changes in the base metal for A285, grade $\mathrm{C}$ and A516, grade 55 steels.

\section{EFFECTS OF GRINDING THE SPECIMEN}

The maximum thickness of nickel plating available on an as plated sample was only about 2 mils and a relatively small number of samples were examined, see table 3. No significant variation is apparent between the as plated and the ground samples in the data in figures 3 and 4 . All samples in the 0 to 2 mil thickness range remain within the $95 \%$ confidence intervals for the data in figure 6 . The as plated samples have a different slope in figure 5, but the amplitude data at $5 \mathrm{KHz}$ appears to be quite sensitive to all material variables. The results of this study show no apparent effects of the grinding operation on the eddy current response to nickel plating thickness, in the 0 to 2 mil range, for the samples examined. A sufficient number of samples were not available to effectively evaluate the results of grinding the specimen.

The grinding operation is a potentially dangerous one, when the plating thickness of the ground sample is being measured using eddy current techniques, but unless a better method is developed to produce uniform thickness on plating reference standards, the grinding will necessarily continue. A few general good practice rules should be followed during the grinding procedure. The specimen should be kept as cool as possible during grinding, and the samples should be completely demagnetized following the grinding operation.

\section{RESIDUAL MAGNETISM}

Nickel and steel are ferromagnetic materials and under certain conditions both can be magnetized. Residual magnetism picked up by either the nickel plating or the steel base can affect eddy current response. These type of reference standards should never be stored in or near magnetic fields which are stronger than the normal field of the earth, and the standards should be periodically demagnetized to remove residual magnetism that can be induced during normal handling. 
REFERENCES

1. Dodd, C. V., "A Portable Phase-Sensitive Eddy Current Instrument," Materials Evaluation, Vol. 26, March 1968, p. 33.

2. Dodd, C. V., "Applications of a Phase-Sensitive Eddy Current Instrument," Materials Evaluation, Vol. 22, June 1964, p. 260.

3. Practical Nickel Plating, The International Nickel Co., 2nd ed., New York, N. Y., 1959.

4. ASTM Standards A285 and A516.

5. Bewley, H. D. and Green, C. H., The Measurement of Nickel Plate on Mild Steel, Paducah Gaseous Diffusion Plant, Paducah, Kentucky.

6. Dodd, C. V., Deeds, W. E., and Luguire, J. W., Integral Solutions to Some Eddy Current Problems, Union Carbide Corporation, Nuclear Division, Oak Ridge National Laboratory, Oak Ridge, Tennessee, April 1969 (ORNL-4384). 
1- 2. Administrative Offices

Stief, S. S.

Winkel, R. A.

3. Computing Technology Center Allen, C. L.

4. Engineering Division

Patton, F. S.

5- 6. Fabrication \& Maint. Div. Krieg, E. H., Jr. Studinger, L. A.

7. Gaseous Diffusion Dev. Div. Trammell, H. E.

8-18. Laboratory Division Anderson, L. W. Arendt, J. W. Barton, J. C. Blake, H. W. Hall, W. H. (2) Napolitan, D. S. Petit, G. S. Seaborn, G. B. Smith, J. H. Warner, J. F.

19-27. Library Fraser, R. J.

28-29. Operations Analysis \& LRP Div. Lang, D, M. Pasquier, L. P.

30. Operations Division Legeay, A. J.

31. Separation Systems Div. Wi.lilamson, R. A.

32. Shift Operations \& Pollution Control Hartman, W. C.

EXTERNAL

59-275. TID-4500 